\title{
Expression of apoptotic markers in patients with oral squamous cell carcinoma (OSCC)
}

\author{
Suni Ann Thomas and Sethupathy. S \\ Division of Biochemistry, Rajah Muthiah Medical College, Chidambaram
}

\begin{abstract}
Oral cancer is one of the ten most common cancers worldwide and accounts for $30-40 \%$ of all cancers detected in India. In normal circumstances, the process of apoptosis effectively eliminates genetically damaged cells from tissues to guard against their continued growth and progression toward malignancy. Dysregulation of apoptosis has been involved in carcinogenesis. Hence oral cancer tissues were examined and markers (bcl-2 and bax expression along with p53) were analysed using immunohistochemistry. In the present study we observed overexpression of p53 and bcl2 and decreased expression of bax in patients with oral squamous cell carcinoma. Thus altered apoptotic mechanism can be accounted for oral carcinogenesis.
\end{abstract}

Key words: P53, immunohistochemistry, apoptosis, bcl2, bax

\section{Introduction}

Oral cancer is one of the ten most common cancers worldwide and accounts for $30-40 \%$ of all cancers detected in India. Despite advances in surgery, radiotherapy and chemotherapy over the past 20-30 years, no significant improvement in the prognosis for oral cancer has been observed. So early detection of oral cancer reduce the morbidity and mortality associated with malignant transformation of oral carcinogenesis [1].

So far, the only accepted method to quantify the risk of progression to OSCC of a potentially malignant lesion is the presence/absence of histological findings of dysplasia, although the presence of dysplasia does not always indicate malignant transformation and its absence do not preclude it [2]. Moreover, histological assessment of dysplasia is extremely subjective and prone to inter and intra-observer variation and additionally some potentially malignant lesions do not show dysplastic alterations [3]. These considerations have stimulated intense research in this area, and many studies have been conducted so far, in an attempt to find out molecular markers that are associated with OSCC and that can predict malignant transformation when found in epithelial precursor lesions, especially in cases without signs of dysplasia [4].

In normal circumstances, the process of apoptosis effectively eliminates genetically damaged cells from tissues to guard against their continued growth and progression toward malignancy. P53 gene exists on chromosome $17 \mathrm{p}$ and behaves as a tumor suppressor. P53 gene not only participates in cell proliferation control, but also plays a role in elimination of cells with DNA damage by induction of apoptosis. B cell lymphoma 2 (Bcl2) is the first gene shown to be involved in apoptosis and was regarded as a proto oncogene that suppresses the cell death rather than stimulating cell proliferation. The human Bcl2 protein is an intracellular, integral membrane protein with a molecular weight of about 26KD. Bcl2 associated X protein (Bax) promotes apoptosis and its chromosomal location is $19 \mathrm{q}$.

The accumulation of 553 protein in response to DNA damage in vitro is well established and appears to induce growth arrest and apoptosis by the transcriptional regulation of other genes [5]. However mutation of this gene can inactivate this tumor suppressor activity. Mutations and alterations in the p53 gene have been implicated in almost all human cancers and p53 status is therefore one of the most important biomarkers for a variety of cancer types. In normal cells, the p53 protein has a very short half life $(6-20 \mathrm{~min})$ and cannot be detected immuno histo chemically. In contrast, the mutant forms are more stable and thus have an extended half life (6hours) and can be detected using immunohistochemical techniques [6].

Overexpression of Bcl-2 has been reported to protect tumor cells from apoptosis [7] whereas increased Bax expression promotes apoptosis induced by cytotoxic drugs and radiation [8]. Induction of apoptotic process of 553 through up regulation of Bax and down-regulation of Bcl-2 has been suggested to determine death of cells following an apoptotic stimulus [9]. Anti-apoptotic (Bcl-2) and pro-apoptotic proteins (Bax) determine the fate of damaged cells and imbalance in Bcl-2 to Bax ratio result in carcinogenesis [10] . So in this study, we have investigated the expression of the apoptosis- related proteins Bax, Bcl-2, and p53 in OSCC to explore the possible relationship among these apoptotic markers in oral carcinogenesis.

\section{Materials And Methods}

Thirteen age- and sex-matched healthy controls formed the first group $(\mathrm{HC}, \mathrm{n}=13)$. Clinically diagnosed and histopathologically confirmed cases of oral cancerous cases (OSCC, $\mathrm{n}=13$ ) formed the second group. The samples were collected from the Department of Oral surgery, Rajah Muthiah Dental College. The 
age ranged from 40 to 60 years. The study was approved by Institutional Human Ethical Committee of Rajah Muthiah Medical College and informed consent was obtained from all subjects before sample collection. Patients with diabetes mellitus or any other systemic diseases were excluded from the study.

All subjects were subjected to biopsy procedure and specimens were fixed in $10 \%$ of neutral buffered formalin and embedded in paraffin wax and H\&E staining done for all the samples before proceeding to immunohistochemistry staining. Formalin fixed paraffin embedded blocks were sectioned at $4 \mu \mathrm{m}$ and transferred to precoated slide [(Bio Genex Optiplus ${ }^{\mathrm{TM}}$ ) Bio Genex, Fremont, CA]. The sections were deparaffinised in xylene and rehydrated in ethanol solution. Antigen retrieval was performed in 10mM citrate buffer (pH6.0) using a pressure cooker $(10 \mathrm{~min})$ and cooled at room temperature. Endogenous peroxidase was blocked with $0.3 \%$ $\mathrm{H}_{2} \mathrm{O}_{2}$ in methanol for $30 \mathrm{~min}$. Non specific binding was blocked with protein block solution for 8 min at room temperature. Following rinsing with wash buffer, sections were incubated for $1 \mathrm{hr}$ with antihuman p53 mouse monoclonal antibody (Novocastra, New castle, UK RTU -ready to use), bcl2 for 30 min at a 1:50 dilution (Path insitu, Minnesota, USA), Bax incubated for $30 \mathrm{~min}$ (Biogenex San Ramon CA). The sections were then incubated with their corresponding secondary antibodies, (Horseradish Peroxidase, Thermoscientific, Fremont, $\mathrm{CA}$ ) for 30 minutes at room temperature. The antigen- antibody complex was detected using 3, 3' diaminobenzidine (DAB) (Sigma, St.Louis, MO, USA). The immunostained slides were counterstained with mayer's hematoxylin for 5 minutes and covered with a mounting medium. Negative controls were employed in which the primary antibody was replaced by phosphate buffered saline. Positively stained cells were counted under a microscope using $200 \mathrm{X}$ magnification in a minimum of five selected areas with frequent positive staining.

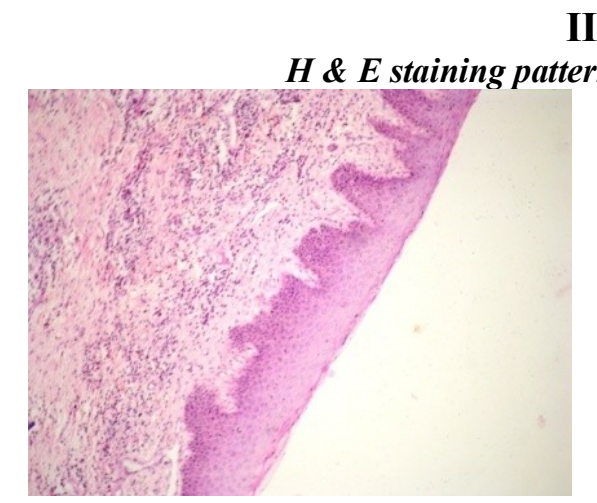

(a)

\section{Results}

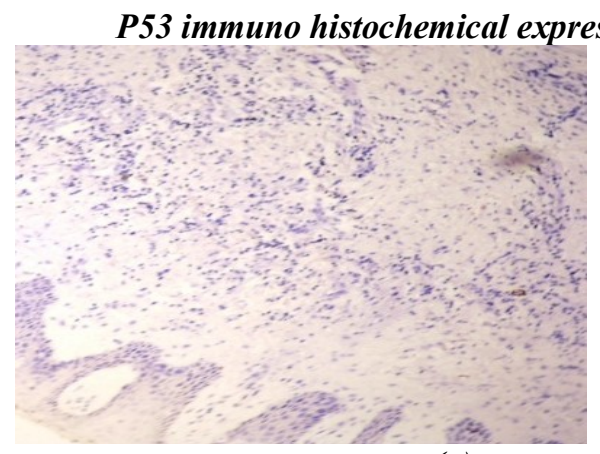

(a)

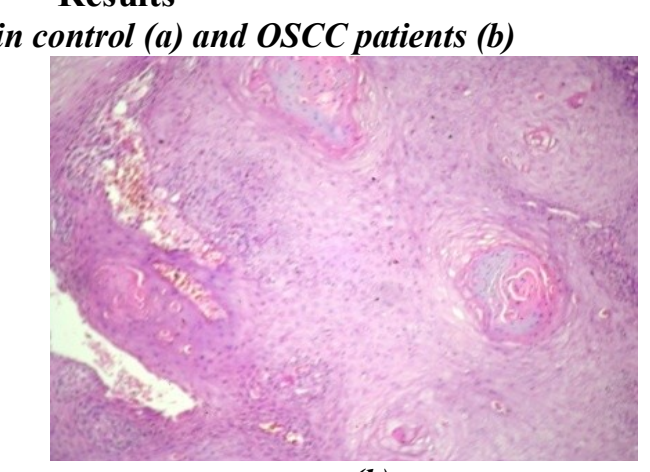

(b)

Bcl2 immuno histochemical expression pattern in controls (a) and OSCC patients (b)

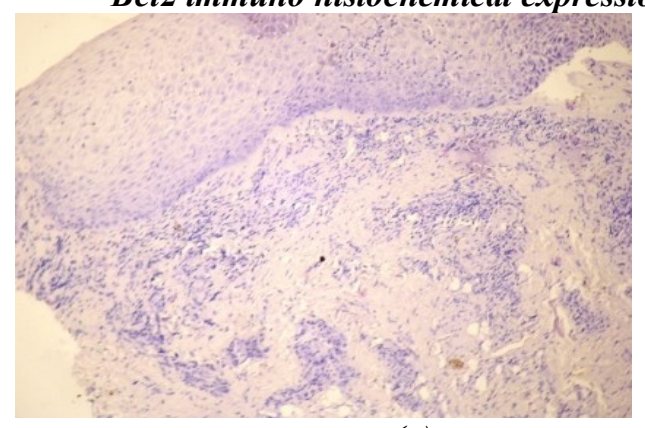

(a)

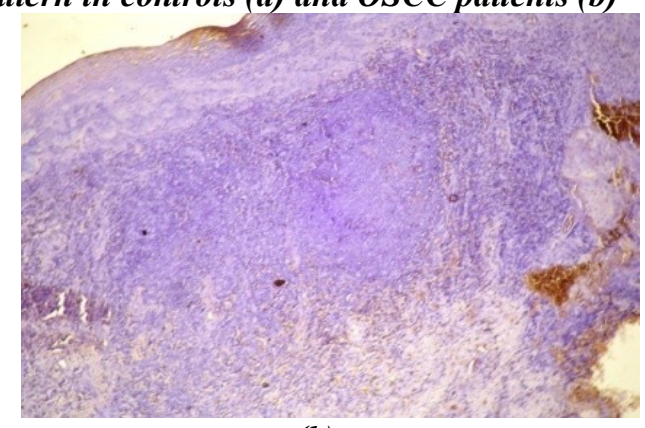

(b) 


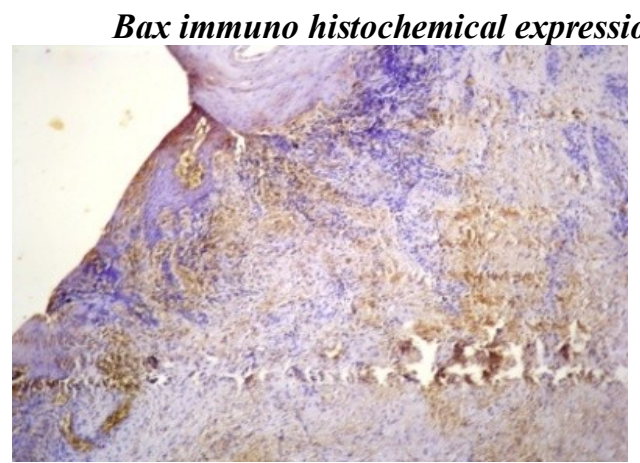

(a)

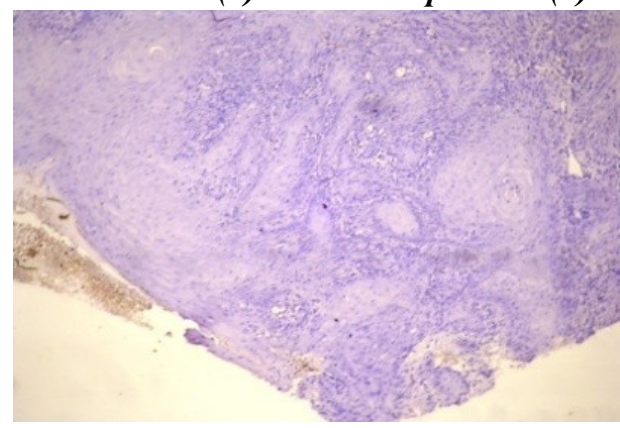

(b)

Table: 1Comparison of staining intensity in OSCC patients with controls

\begin{tabular}{|c|c|c|c|c|c|c|c|c|c|c|c|c|}
\hline Samples & \multicolumn{4}{|c|}{ P53 } & \multicolumn{4}{|c|}{$\mathrm{Bcl} 2$} & \multicolumn{4}{|c|}{ Bax } \\
\hline Staining intensity & 0 & $1+$ & $2+$ & $3+$ & 0 & $1+$ & $2+$ & $3+$ & 0 & $1+$ & $2+$ & $3+$ \\
\hline Controls & 13 & 0 & 0 & 0 & 13 & 0 & 0 & 0 & 6 & 7 & 0 & 0 \\
\hline OSCC & 0 & 3 & 5 & 5 & 2 & 2 & 6 & 3 & 10 & 3 & 0 & 0 \\
\hline
\end{tabular}

0-No expression, 1+- mild, 2+- moderate, $3+$ - strong

\section{Discussion}

The identification of molecular markers that provide an insight into the potential behaviour or aggressiveness of tumors is a necessary step for the improvement of cancer treatment. As per our study, all the OSCC samples showed mutant p53 expression where as none of the control samples showed expression. Bcl2 was expressed in $85 \%$ of OSCC samples where as control samples were negative for bcl 2 expression. Bax expression was low in OSCC samples (23\%) when compared with control samples (57\%). This indicates of a lesser pro apoptotic bax expression which might have contributed to oral cancer.

It is widely accepted that OSCC develops as a result of accumulation of genetic errors in the same tissue [11] and that mutations in the TP53 gene leading to loss of function is one the most common genetic damage found in human tumour and in OSCC. TP53 mutations may result in an over-production of P53 inactive proteins which accumulate in the epithelium or due to delayed/ partial degradation [12].

The balance between cell proliferation and apoptosis determines growth in both normal tissue and in cancer. This balance is controlled by many factors of which the Bcl-2 family, particularly Bcl-2, and Bax, play an important role [13]. The Bcl-2 protein, an anti-apoptotic marker and its over-expression has been reported in several tumors including breast, thyroid, lung and skin carcinomas [14]. In oral carcinomas, over expression of Bcl-2 from $7 \%$ to $60 \%$ has been reported from developed countries while Ravi et al., and Kannan et al., reported $100 \%$ and $23 \%$ Bcl-2 expression respectively, in oral cancers from India[15,16,17]. It has been suggested that apoptosis is a barrier against cancer. In our study all normal epithelium was negative for Bcl-2 expression. Lack of Bcl-2 expression in normal has also been reported by other investigators [18].

The Bcl-2 gene is a proto-oncogene whose protein product inhibits apoptosis. Its role is associated with keeping cells alive, but not by stimulating them to proliferate, as other proto-oncogenes do. Even though increased Bcl-2 expression does not seem to be a required factor for the progression of the neoplastic process, it may play a significant role in early carcinogenesis. The proapoptotic protein Bax plays an important role in defense against cancer as it mediates apoptosis in response to genotoxic stress. It has been shown that Bax can bind to Bcl-2, resulting in inactivation of the antiapoptotic action of Bcl-2 [19]. Bax is expressed in normal epithelium. It has been reported that patients with oral cancer along with Bax expression had a better prognosis than those without Bax expression [20]

Bax expression was noticed in the cytoplasm uniformly in all cell layers of the normal squamous epithelium. Decreased expression of Bax in the cancerous tissues may reduce apoptotic cell death as well as accelerate their growth [21]. A positive association between loss of Bax immune positivity and shorter survival of patients with metastatic breast adeno carcinoma has been shown [22]. An inverse correlation between p53 and Bax immuno staining has been reported in oral carcinoma [23]. Our results support these observations.

\section{Conclusion}

Apoptotic mechanism is dysregulated in oral carcinogenesis as evidenced by expression of mutant $\mathrm{p} 53$ protein along with increased Bcl2 and decreased Bax expression. Further, exonic studies of the mutant p53, in p53 expressed samples can be explored for common mutation. 


\section{References}

[1] Moore SR, Johnson NW, Pierce AM, Wilson DF. The epidemiology of mouth cancer: a review of global incidence. Oral diseases 2000; 6: 65-74.

[2] Gale N, Pilch BZ, Sidransky D, Barnes L, Eveson JW, Reichart P, Sidranski D. Epithelia precursor lesions in Pathology and genetics Head and Neck tumours. World Health Classification of Tumours eds Lyon 2005; 177-179.

[3] Scully C, Sudbo J, Speight PM. Progress in determining the malignant potential of oral lesions. J Oral Pathol Med 2003; 32: 251256.

[4] Cruz I, Snijders PJ, Van Houten V, Vosjan M, Van der Waal I, Meijer CJ. Specific p53 immunostaining patterns are associated with smoking habits in patients with oral squamous cell carcinomas. J Clin Pathol 2002; 55: 834-840.

[5] Oren M. Decision making by p53: life death and cancer. Cell death differ 2003; 10: 431-442.

[6] Poornima C, Agnihotri, Rajan SY, Padmavathi BN, Guruprasad R. The role of p53 in oral cancer - a review. JIAOMR 2005; 17(4): $153-156$.

[7] Reed JC. Bcl-2: prevention of apoptosis as a mechanism of drug resistance. Hematol Oncol Clin North Am 1995; 9: 451-473.

[8] Wagener C, Bargou RC, Daniel PT, Bommert K, Mapara MY, Royer HD, Bernd Dorken. Induction of the death-promoting gene bax-alpha sensitizes cultured breast cancer cells to drug induced apoptosis. Int J Cancer 1996; 67: $138-141$.

[9] Miyashita T, Krajewski S, Krajewska M, Wang HG, Lin HK, Liebermann DA. Tumor suppressor p53 is a regulator of bcl-2 and bax gene expression in vitro and in vivo. Oncogene 1994; 9: 1799-1805

[10] Gao Q, Hu JF, Yu Y. The role of nitric oxide in ethanol postconditioning induced cardioprotection. Zhongguo Ying Yong Sheng Li Xue Za Zhi 2012; 28: 9-13.

[11] Joseph BK: Oral cancer: prevention and detection. Med Princ Pract 2002; 11(1): 32-35.

[12] Phil VCM, Yuen APW, Lam KY, Ho WK, Wei Wi. Prognostic significance of serum p53 protein and p53 antibody in patients with surgical treatment for head and neck squamous cell carcinoma. Head Neck 2001; 25: 286-291.

[13] Mithani SK, Mydlarz WK, Grumbine FL, Smith IM, Califano JA. Molecular genetics of premalignant oral lesions. Oral Dis 2007; 13: 126-133.

[14] Lu QL, Abel P, Foster CS, Lalani EN. Bcl-2: Role in epithelial differentiation and oncogenesis. Hum Pathol 1996; 27: 102-110.

[15] Stoll C, Baretton G, Abrens C, Löhrs U. Prognostic significance ofapoptosis and associated factors in oral squamous cell carcinoma. Virchows Arch 2000; 436: 102-108.

[16] Ravi D, Ramadas K, Mathew BS, Nalinakumari KR, Nair MK, Pillai MR. De novo programmed cell death in oral cancer. Histopathology 1999; 34: 241-249.

[17] Kannan K, Latha PN, Shanmugam G. Expression of bcl-2 oncoprotein in Indian oral squamous cell carcinomas. Oral Oncol 1998; 34: $373-376$

[18] Chang KC, Su IJ, Tsai ST, Shieh DB, Jin YT. Pathologic features of betel quid-related oral epithelial lesions in Taiwan with special emphasis on the tumor progression and human papilloma virus association. Oncology 2002; 63: 362-369.

[19] Lalier L, Cartron PF, Juin P, Nedelkina S, Manon S, Bechinger B, Vallette FM. Bax activation and mitochondrial insertion during apoptosis. Apoptosis 2007; 12: 887-896.

[20] Kato K, Kawashiri S, Yoshizawa K, Kitahara H, Yamamoto E. Apoptosis-associated markers and clinical outcome in human oral squamous cell carcinomas. J Oral Pathol Med 2008; 37: 364-371

[21] Zhang YY, Deng T, Hu ZF, Zhang QP, Zhang J, Jiang H. Mechanisms of inhibiting proliferation and inducing apoptosis of human gastric cancer cell line SGC7901 by ursolic acid. Ai Zheng 2006; 25: 432-437.

[22] Bukholm IR, Bukholm G, Nesland JM. Reduced expression of both Bax and Bcl-2 is independently associated with lymph node metastasis in human breast carcinomas. APMIS 2002; 110: 214-220.

[23] Manoharan S, Sindhu G, Nirmal MR, Vetrichelvi V, Balakrishnan S. Protective effect of berberine on expression pattern of apoptotic, cell proliferative, inflammatory and angiogenic markers during 7,12-dimethyl benz(a)anthracene induced hamster buccal pouch carcinogenesis. Pak J Biol Sci 2011; 14(20): 918-932. 